\title{
SAÚDE DO TRABALHADOR - DIAGNÓSTICO DE SITUAÇÃO NO HOSPITAL VETERINÁRIO "GOVERNADOR LAUDO NATEL" DA FACULDADE DE CIÊNCIAS AGRÁRIAS E VETERINÁRIAS DA UNIVERSIDADE ESTADUAL PAULISTA “JÚLIO DE MESQUITA FILHO”, JABOTICABAL - SP
}

\author{
WORKER'S HEALTH - DIAGNOSIS OF SITUATION IN VETERINARY HOSPITAL \\ “GOVERNADOR LAUDO NATEL” IN FCAV/ UNESP, JABOTICABAL - SP
}

\author{
A. M. TEDESCO ${ }^{*}$, M. J. L. SICONELLI², N. A. ASSIS ${ }^{3}$, K. P. BÜRGER ${ }^{4}$
}

\begin{abstract}
RESUMO
Diante do Decreto-lei 5.452, o médico veterinário, com sua formação abrangente, pode em conjunto a outros profissionais, integrar e estabelecer os potenciais perigos envolvidos nas atividades dos trabalhadores, levando conhecimento e, assim, atuando na prevenção de agravos a saúde dos profissionais envolvidos. Em vista disso, objetivou-se realizar o diagnóstico de situação sobre a saúde do trabalhador do Hospital Veterinário "Governador Laudo Natel" (HV) da FCAV/ UNESP, câmpus de Jaboticabal. Foi realizada a investigação com 33 funcionários, dividindo-a entre inquérito e investigação sorológica. Na primeira etapa, as questões revelaram o grau de entendimento que cada trabalhador possuía sobre seus direitos, os conhecimentos específicos no exercício de sua profissão na área da saúde e a preocupação da instituição empregatícia com a saúde do trabalhador. Na segunda etapa foi realizado o levantamento sorológico para leptospirose pelo teste de soroaglutinação microscópica (SAM), considerado "Gold Standard" e recomendado pela Organização Mundial da Saúde (OMS), utilizando-se de 24 sorovares. Verificou-se que, embora 87,88\% (29/33) dos funcionários saibam a necessidade do uso de Equipamentos de Proteção Individual (EPIs), 12,12\% (4/33) ainda não os utilizam, necessitando-se de maior difusão e conscientização sobre seu trabalho, além da importância de protegerem e cuidarem da própria saúde. Somente uma amostra foi reagente $(3,03 \%)$, indicando, assim, possível contato do trabalhador com o microrganismo causador dessa enfermidade ou até mesmo uma inespecificidade do teste, uma vez que o trabalhador não apresentava nenhum sintoma compatível com a enfermidade. Portanto, observa-se a necessidade de melhor difusão de treinamentos técnicos ou exposições orais de exemplos do dia-a-dia na busca de aprimorar a educação e os conhecimentos técnicos dos trabalhadores, garantindo a redução de perigos à saúde do trabalhador.
\end{abstract}

PALAVRAS-CHAVES: INQUÉRITO. LEPTOSPIROSE. SAM. VIGILÂNCIA EM SAÚDE.

AGRADECIMENTOS: Laboratório de exames sorológicos de leptospirose e brucelose.

ÁREA TEMÁTICA: Saúde Pública. 